\title{
DURABLE PRESS TREATMENTS TO COTTON, VISCOSE, BAMBOO AND TENCEL FABRICS
}

\author{
Shabiya Thaseen ${ }^{1}$ \\ ${ }^{I}$ Department of PG Studies and Research in Home Science, Textile Science and Fashion Designing, J.B.A.S. Womens \\ College, Teynampet, Chennai - 600018
}

\begin{abstract}
Durable press finishing processes are generally used in the textile industry to produce wrinkle-free fabrics and garments. A durable press finishing agent forms covalent bonds with cellulosic hydroxyl groups, thus crosslinking the cellulose molecules. The cross linking of cellulose increase creases resistance of treated fabrics, and in the case of cotton, reduces its strength. Crease recovery angle (CRA) and tensile strength are the two most important parameters which are used to evaluate the performance of the crosslinked cellulosic fabrics and garments. In this study, we investigated the effect of DMDHEU resin on the crosslinking of cotton, bamboo, tencel and viscose fabrics. Three levels of resin concentration and four levels of curing temperature were employed for crosslinking treatments. The curing time was kept at 4 min in all the cases.
\end{abstract}

The results show that the crease recovery angle has improved in all the cases and the improvement was found to be excellent for viscose, With the exception of cotton, in all the other cases, the tensile strength was unchanged. Thus resin treatment is strongly recommended for bamboo, viscose and tencel fabrics as it is found to improve wrinkle resistance without causing any deterioration in strength.

\section{INTRODUCTION}

The 'Durable press' process, which is also known as the "Permanent press" process, first appeared in the market in 1964. German patent 339623 is on this process and Foulds, Marsh and Wood (1929) used phenol formaldehyde and urea-formaldehyde to form resins on cotton fabric. Bajaj (2002) has dealt with resin finishing in her lengthy paper. Recently, Dehabadi et al (2013) have published an extensive review on the durable press finishing of cotton fabrics. The crease resistant finishes involved padding cotton fabric with low molecular weight precondensates of amino-aldehyde or other resins followed by drying and curing under tension at temperatures upto $160^{\circ} \mathrm{C}$ for a short period. The resin could crosslink cellulose chains in amorphous regions to prevent chain slippage that leads to fabric wrinkles.

Lyocell has a higher crystallinity (Colom et al 2002) and amorphous orientation which are responsible for its higher wet strength. Information on resin finishing of advanced man made cellulosic fibres such as tencel is scant, and it will be desirable to carry out work in this direction. Work has been done on BTCA treatment of ramie yarns and the results have been reported (Zhou et al., 2002). In 1918, a team of scientists at Tootal Broadhurst Lee company applied urea formaldehyde on cotton to impart crease resistant fabrics.

Sunder and Nalankilli (2012) have done extensive work on the effect of poly carboxylic acids on cotton fabrics and have found that the use of polycarboxylic acids such as maleic acid, citric acid and tartaric acid for cotton fabrics instead of the conventional DMDHEU has improved the crease recovery to the same level. However the strength losses were found to be lower and flexural rigidity was also found to be lower and soil resistance was found to improve. The FTIR spectroscopic studies showed the formation of ester crosslinks between cellulose and polycarboxylic acids. It was found that, when applied as such, maleic acid and itaconic acid provide better results than the other two PCAs, whereas in combination citric acid with other PCAs provides - synergic effect in imparting functional properties. Also, using BTCA, a considerable amount of work was carried out on ramie and other fibres. Crosslinking of cellulose and replacement of weak forces between cellulose molecules with stronger covalent or ionic bonds that are more resistant towards the effects of water and external deformation forces is another way of improving the wrinkle recovery of fabrics. This was accomplished by the use of DMDHEU, N N-Dimethylol-4,5-dihydroxyethylene urea. The major disadvantage is that it releases formaldehyde during the curing process. So either to develop agents with low formaldehyde content or surface active agents that are completely formaldehyde free were the choices (Hashem et al 2009, Hebeish et al 1979, Ibrahim 1982, Schramm et al 2002, Turner 1988).

Research workers have found that polycarboxylic acids (PCAs) can enter into esterification reaction with cellulose through the formation of a cyclic anhydride intermediate. Yang and Xu (1998), and Wie and Yang (2000) have studied the effect of homopolymer and terpolymer of maleic acid (PMA \& TPMA) in combination with citric acid (CA) on cotton fabric. It has been found that the combination of TPMA/CA is more effective than the PMA/CA combination. Xu et al (2000) first treated the fabric with citric acid and then with BTCA and compared the results. In single step method, the fabric was treated with a mixture of 
these two acids. Crease recovery angle, tensile strength, tearing strength and strength retention were measured for samples prepared under these two methods and the results compared. Wu and Yang (2007) also studied the reactions of maleic acid and sodium hypophosphite (SHP) as catalysts on cotton and the effectiveness of this treatment on flammability and crease recovery.

There are three approaches to improve wrinkle recovery, namely, cross linking of cellulose, lubrication with softening agents and a combination of cross linking and lubrication. An attempt was made to reduce formaldehyde. The disadvantages of using N, N-dimethyl-4,5-dihydroxy ethylene area (DMeDHEU) or polycarboxylic acids (citric acid 1,2,3,4-butane tetra carboxylic acid, BTCA) are tensile and tear strength loss, discolouration (yellowing) after treatment and higher costs. Additionally, ionic cross-linking can stabilize cellulose and improve wrinkle recovery of cotton. It is also a fact that new cross-linking agents, which have been developed as alternatives to DMDHEU, have not become successful due to their high costs, and lower wrinkle recovery. Manian and Bechtold (2005) have looked at the drying rates in resin treatment of lyocell fabrics. The effect of drying rate on the distribution of cross linking agents in treated lyocell fabrics is similar to that reported for other cellulosics but the effect of reagent distribution on the performance of treated lyocell is different from that reported for other cellulosics.

The aim of this study was to investigate the response of cotton viscose, tencel and bamboo fabrics to resin finishing process using the DMDHEU resin. Over the years, many cellulose derivatives have been developed such as tencel and bamboo and it will be interesting to compare the changes in the properties of fabrics made by these fibres following durable press finishes. The functional properties imparted on the finished fabrics have been tested as per international standards. It is found from literature that no systematic study has been done on this area.

\section{MATERIALS}

Four fabrics were woven using Ne 30 produced from $100 \%$ cotton, $100 \%$ viscose, $100 \%$. Tencel and $100 \%$ bamboo fibres. The following Table 1 gives details of the fabric samples used.

Table 1: Details of fabrics

\begin{tabular}{|l|l|l|l|l|l|l|l|}
\hline S.No. & $\begin{array}{l}\text { Type of } \\
\text { fabrics }\end{array}$ & Ends/cm & Picks/cm & $\begin{array}{l}\text { Warp count } \\
\text { Ne }(\text { Tex) }\end{array}$ & $\begin{array}{l}\text { Weft count } \\
\text { Ne(Tex) }\end{array}$ & GSM & $\begin{array}{l}\text { Thickness } \\
(\mathbf{m m})\end{array}$ \\
\hline 1. & Cotton & 26 & 24 & $30(19.68)$ & $30(19.68)$ & 120 & 0.33 \\
\hline 2. & Viscose & 26 & 24 & $30(19.68)$ & $30(19.68)$ & 120 & 0.31 \\
\hline 3. & Tencel & 26 & 23 & $30(19.68)$ & $30(19.68)$ & 122 & 0.34 \\
\hline 4. & Bamboo & 26 & 22 & $30(19.68)$ & $30(19.68)$ & 121 & 0.34 \\
\hline
\end{tabular}

\subsection{Chemicals}

All the fabrics were washed and cotton was desized, scoured and bleached.

DMDHEU and $\mathrm{MgCl}_{2} \cdot 6 \mathrm{H}_{2} \mathrm{O}$ of analytical grade were used. Before treatment, all the fabrics were washed with distilled water and dried. The fabrics were treated with DMDHEU (Dimethylol dihydroxy ethylene urea) resin at various concentration and catalyst.

The following formulation was used:

\subsection{Formulation}

\begin{tabular}{ll} 
DMDHEU (44\% solid) & $-80,100,140 \mathrm{~g} / \mathrm{l}$ \\
$\mathrm{MgCl}_{2} \cdot 6 \mathrm{H}_{2} \mathrm{O}$ & \multicolumn{1}{c}{$-20 \mathrm{~g} / \mathrm{l}$} \\
Polyethylene emulsion & $-25 \mathrm{gpl}$ \\
Acrylic emulsion & $-30 \mathrm{~g} / \mathrm{l}$ \\
Non ionic wetting agent & $-2 \mathrm{~g} / \mathrm{l}$
\end{tabular}

\subsection{Treatment conditions}

$\begin{array}{lc}\text { Padding } & -100 \% \text { wet pick up } \\ \text { Drying } & -100^{\circ} \mathrm{C}, 2 \text { min } \\ \text { Curing } & -120^{\circ} \mathrm{C}, 135^{\circ} \mathrm{C}, 150^{\circ}, 160^{\circ} \mathrm{C} \\ \text { Time } & -4 \text { min }\end{array}$

Required quantity of water was added to the above to make up one litre of padding liquor. In addition to DMDHEU and $\mathrm{MgCl}_{2}$, the formulation contains a polyethylene emulsion which is a softener for improving fabric hand and strength. A wetting agent is used to promote absorption of finish during the padding step. The padding was done on a padding mangle and the pressure was adjusted for $100 \%$ expression. The samples, after curing, were subsequently washed with 5 gpl of $\mathrm{NaCO}_{3}$ at $50^{\circ} \mathrm{C}$ for 5 minutes to remove the unreacted chemicals then rinsed and air dried.

Fabric samples were padded, squeezed with a pressure of 3 $\mathrm{kg} / \mathrm{cm}^{2}$, dried at $80^{\circ} \mathrm{C}$ for $10 \mathrm{~min}$ followed by curing at $160^{\circ} \mathrm{C}$ for $5 \mathrm{~min}$. The samples were washed and dried. The cured cotton, viscose tencel and bamboo were evaluated for their performance after one washing drying cycle to remove the unreacted reagents and the catalyst. A standard method was used to measure the conditioned wrinkle recovery angle (AATCC66-2008) and conditioned tensile strength (ASTMD1424-09). 
Table 4: Effect of resin concentration on crease recovery and tensile strength

\begin{tabular}{|c|c|c|c|c|c|}
\hline \multirow[b]{2}{*}{ Material } & \multirow{2}{*}{$\begin{array}{l}\text { Resin } \\
\text { concentration } \\
\text { (\%) }\end{array}$} & \multirow[b]{2}{*}{ Curing Temp } & \multirow{2}{*}{$\begin{array}{l}\text { Total } \\
\text { (CRA) }\end{array}$} & \multicolumn{2}{|c|}{ Tensile strength } \\
\hline & & & & Warp (kgf) & Weft (kgf) \\
\hline \multirow{3}{*}{ Cotton } & 8 & \multirow{3}{*}{$\begin{array}{l}160^{\circ} \mathrm{C} \\
4 \mathrm{~min}\end{array}$} & 190 & 21.7 & 16.4 \\
\hline & 10 & & 222 & 21.2 & 16.2 \\
\hline & 14 & & 224 & 21.9 & 16.3 \\
\hline \multirow{3}{*}{ Viscose } & 8 & \multirow{3}{*}{$\begin{array}{l}160^{\circ} \mathrm{C} \\
4 \text { min }\end{array}$} & 209 & 24 & 18 \\
\hline & 10 & & 228 & 23 & 17 \\
\hline & 14 & & 238 & 22 & 15 \\
\hline \multirow{3}{*}{ Tencel } & 8 & \multirow{3}{*}{$\begin{array}{l}160^{\circ} \mathrm{C} \\
4 \text { min }\end{array}$} & 205 & 34 & 26 \\
\hline & 10 & & 223 & 33 & 24 \\
\hline & 14 & & 224 & 32 & 21 \\
\hline \multirow{3}{*}{ Bamboo } & 8 & \multirow{3}{*}{$\begin{array}{l}160^{\circ} \mathrm{C} \\
4 \mathrm{~min}\end{array}$} & 199 & 24 & 19 \\
\hline & 10 & & 222 & 23 & 18 \\
\hline & 14 & & 226 & 22 & 15 \\
\hline
\end{tabular}

\section{RESULTS AND DISCUSSION}

The crease recovery behavior of all fabrics treated with DMDHEU is observed to be very good. Crease recovery angle (CRA) for untreated fabrics ranges between $158^{\circ} \mathrm{C}$ to $238^{\circ}$ while for resin treated, it ranges, between $187^{\circ}-234^{\circ}$. This clearly shows that crosslinking effected by the esterification reaction of the DMDHEU with cellulose has imparted better recovery behavior. Among the fabrics, cotton shows the lowest value of CRA at $120^{\circ} \mathrm{C}$ curing temperature while viscose, tencel and bamboo show higher values. With the increase in temperature, the crease recovery shows in increase. Bamboo and viscose fabrics show low strength while tencel show higher strength. Table 2 shows the crease recovery and tensile strength of the control samples. Lyocell fabrics in untreated states shows the highest strength which is expected.

Table 2: Crease recovery angle (CRA) and strength properties of parent (untreated) samples

\begin{tabular}{|c|c|c|c|}
\hline \multirow[b]{2}{*}{ Sample } & \multirow{2}{*}{$\begin{array}{l}\text { Total } \\
\text { CRA } \\
\text { (Warp \& } \\
\text { Weft) }\end{array}$} & \multicolumn{2}{|c|}{ Tensile strength } \\
\hline & & Warp (kgf) & Weft (kgf) \\
\hline Cotton & 158 & 30 & 19.8 \\
\hline Tencel & 197 & 33.2 & 26.7 \\
\hline Viscose & 189 & 26.4 & 18.3 \\
\hline Bamboo & 180 & 24.0 & 17.1 \\
\hline
\end{tabular}

Table 3: CRA and strength properties of treated samples at different curing temperatures

\begin{tabular}{|c|c|c|c|c|}
\hline \multirow[b]{2}{*}{ Material } & \multirow{2}{*}{$\begin{array}{l}\text { Curing } \\
\text { temp }{ }^{\circ} \mathrm{C}\end{array}$} & \multirow[b]{2}{*}{ CRA } & \multicolumn{2}{|c|}{ Tensile strength } \\
\hline & & & $\begin{array}{l}\text { Weft } \\
\text { (kgf) }\end{array}$ & $\begin{array}{l}\text { Warp } \\
(\mathbf{k g})\end{array}$ \\
\hline \multirow{4}{*}{ cotton } & 120 & 190 & 27.2 & 18.5 \\
\hline & 135 & 213 & 27.0 & 18.2 \\
\hline & 150 & 223 & 26.8 & 18.1 \\
\hline & 160 & 225 & 26.4 & 18.0 \\
\hline \multirow{3}{*}{ Viscose } & 120 & 209 & 26.1 & 18.3 \\
\hline & 135 & 223 & 26.2 & 18.3 \\
\hline & 150 & 228 & 21.7 & 18.3 \\
\hline
\end{tabular}

\begin{tabular}{|l|l|l|l|l|}
\hline & 160 & 234 & 22.7 & 16.4 \\
\hline \multirow{4}{*}{ Tencel } & 120 & 202 & 24.8 & 34.0 \\
\cline { 2 - 5 } & 135 & 221 & 28.7 & 34.0 \\
\cline { 2 - 5 } & 150 & 223 & 27.5 & 33.0 \\
\cline { 2 - 5 } & 160 & 224 & 27 & 33.6 \\
\hline \multirow{4}{*}{ Bamboo } & 120 & 187 & 26 & 20 \\
\cline { 2 - 5 } & 135 & 205 & 25.8 & 19 \\
\cline { 2 - 5 } & 150 & 222 & 25.1 & 19.5 \\
\cline { 2 - 5 } & 160 & 225 & 24 & 18 \\
\hline
\end{tabular}

It is apparent from Table 4 that as resin concentration increases, the crease recovery increases in all the cases. It is also noticed that viscose fabric shows a superior performance in comparison to other fabrics in terms of crease recovery values. With regard to tensile tests, it is apparent that with the exception of cotton tensile strength is unaffected in bamboo, tencel and viscose. The reasons for this are that the covalent bond which is formed as a result of crosslinking has led to an increase in strength. For tencel, the improved crease recovery results agree with the findings of Manian and Bechtold (2005). Also, data on yarn strength of untreated and treated of lyocell show that the resin treatment has led to lower strength. The crease recovery is best for tencel followed by viscose. Cotton shows the least crease recovery which is a well known fact. Our results are found to be contradictory to the observations made by Manian and Bechtold (2005).

Further, studies on FTIR analysis of crosslinked fabrics are in progress and the results will be reported later.

\section{CONCLUSIONS}

Resin finish has not affected the strength of fabrics made from viscose, tencel and bamboo. The crease recovery of all fabrics has improved with the resin treatment and curing temperature. 


\section{ACKNOWLEDGEMENTS}

The author would like to acknowledge her indebtedness to Dr. Venkatraman Subramaniam, Jaya Engineering College, Chennai for his various advices.

\section{REFERENCES}

[1] Bajaj, P., Finishing of textile materials, J. Appl. Polym. Sci., vol. 83, pp.631-659, 2002.

[2] Chen, D., Yang, C.Q. and Qiu, X., Aqueous polymerization of maleic acid and cross-linking of cotton cellulose by poly (maleic acid), Ind. Eng. Chem. Res., vol.44, pp.7921-7927, 2005.

[3] Colom, X, Carrillo, F, Crystallinity charges in lyocell and viscose-type fibres by caustic treatment, European Polymer Journal, 38, 2225-2230, 2002.

[4] Dehabadi, V.A., Buschmann, H.J., Gutman, J.S., Durable press finishing of cotton fabrics : An overview. Textile Res. J., vol.83, pp.1974-1995, 2013.

[5] Foulds, R., Marsh, J. and Wood, F. BP291473, BP291474, US patent 17345161929.

[6] Hashem, M., Ibrahim, N.A., El-Shafei, A., et al., An eco-friendly novel approach for attaining wrinkle-free/softhand cotton fabric, Carbohyd Polym, vol.78, pp.690-703, 2009.

[7] Hebeish, A., Nassar, F.A., Ibrahim, N.A., et al., Studies of some basic aspects in easy care cotton finishing, IV. Effect of acid scavengers on free formaldehyde in and strength of crosslinked cotton, Angew Makromol Chem., vol.82, pp.27-37, 1979.

[8] Ibrahim, N.A. and Hebeish, A., The problem of free formaldehyde in cellulosic-containing durable press fabric, Colour Rev., vol.313, pp.2-4, 1982.

[9] Jang, K.O. and Yeh, K., Effects of silicone softeners and silane coupling agents on the performance properties of cotton fabrics, Textil. Res. J., vol.63, pp.557-565, 1993.

[10] Manian, A.P. and Bechtold T., Drying Rates in Resin Treatment on Lyocell fabrics, Textile Res. J., vol.75, no.3, pp.258-264, 2005.

[11] Schramm, C., Bischof-Vukusic, S. and Katovic, D., Non-formaldehyde durable press finishing of dyed fabrics: evaluation of cotton-bound polycarboxylic acids, Color Technol., vol.188, pp.244-249, 2002.

[12] Sunder, A.E. and Nalankilli, G., Polyfunctional finishes on cotton textiles, Ind. J.F. \& Text. Res., Vol.37, pp.364-371, 2012.

[13] Turner, Jd., Improving the DP appearance of cotton fabrics with additives and aminofunctional silicones, Text. Chem. Color, vol.20, pp.36-38, 1988.

[14] Weilin Xu, Weigang, Cui, Wenbin Li and Weiqi Geo, Two step durable press, treatment of cotton fabric, Colour Technol., pp.117, no.6, pp.352-355, 2001.

[15] Weish Wei and Charles Q Yang, Polymeric carboxylic acid and citric acid as non formaldehyde Durable Press Finish, Text. Chem. Color, vol.32, pp.53, 2000.
[16] Xialing $\mathrm{Wu}$ and Charles Q Yang, Flame retardant finishing of cotton fabric using maleic acid and sodium hypophosphite, AATCC Rev, vol.7, pp.35, 2007.

[17] Xu, W. and Li, Y., Cotton fabric strength loss from treatment with polycarboxylic acids for durable press performance, Textil. Res. J., vol.70, pp. 957 961, 2000.

[18] Yang, CQ, Xu, L, Shiqi Li, Jiang Y, Non formaldehyde Durable press finishing of cotton fabrics by combining Citric Acid with Polymers of Maleic acid. Textile Research Journal, vol.68(6), pp.457-464, 1998.

[19] Zhou, L.M., Yeung, K.W. and Yuen, C.W.M. Effect of mercerization on the crosslinking of Ramie Fabic using 1,2,3,4 butane tetra carboxylic acid. Physical properties and crosslink distribution, Textile Res. J., vol.72, 795-802, 2002.

[20] Zhou, L.M., Yeung, K.W.P. and Yuen, C.W.M., Effect of $\mathrm{NaOH}$ mercerization on the crosslinking of Ramie yarn using 1,2,3,4-Butane tetracarboxylic acid. Textile Res. J., vol.72, pp.531-538, 2002. 